Social media is revolutionizing the way we live, learn,

work, and play.

Elements of the private sector have begun to thrive on opportunities to forge,

build, and deepen relationships. Some

are transforming

their organizational

structures and

opening their corporate ecosystems

in consequence.

The public sector

is a relative newcomer. It too can drive stakeholder involvement and satisfaction.

\title{
Social Media and the Public Sector
}

\section{By Olivier Serrat}

\section{R.I.P. Web 1.0}

Global conversations, especially among Generation $Y,{ }^{1}$ were born circa 2004. Beginning 1995 until then, the internet had hosted static, one-way websites. These were places to visit passively, retrieve information from, and perhaps post comments about by electronic mail.

Sixteen years later, Web $2.0^{2}$ enables many-to-many connections in numerous domains of interest and practice, powered by the increasing use of blogs, image and video sharing, mashups, podcasts, ratings, Really Simple Syndication, social bookmarking, tweets, widgets, and

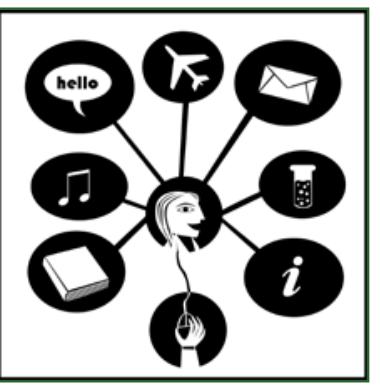
wikis, among others. Today, people expect the internet to be user-centric.

Web 1.0 was about getting people connected, even though its applications were largely proprietary and only displayed information their owners wished to publish. More advanced (and cheap or free) software can now assume, correctly, that people stand ready to connect; it is therefore far more interactive and people-aware. Users generate content (e.g., blogs, Flickr, wikis), business intelligence (e.g., FreshBooks, Prosper), reviews and opinions (e.g., TripAdvisor), products (e.g., eBay), networks of contacts (e.g., Facebook, MySpace), statements on the value of web pages (e.g., Google PageRank), distributed storage and server capacity (e.g., Peer-to-Peer networks), connectivity (e.g., mesh networks, Wi-Fi sharing), and expressions of taste and emotion (e.g., Delicious, Last.fm) that search engines, not portals, fetch. Since traffic equals money, simple online economics drive uninterrupted change in the way we live, learn, work, and play.

Generation Y (also known as the Millennial Generation, Generation Next, or the Net Generation) describes the demographic group born between the mid-1970s and the early 2000s, with ages ranging 10-35 years. It is characterized by growing familiarity with communications, media, and digital technologies.

The term "Web 2.0" refers to applications that facilitate interactive information sharing, interoperability, usercentered design, and collaboration on the internet. These are the result of cumulative changes in the ways software developers and users employ the internet as an information transport mechanism. Typical features and techniques include search, links, authoring, tags, extensions, and signals. 
The form that communications take is collectively dubbed as "social media". ${ }^{3}$ Where that is enriched by high levels of user interactions, the contents of the platforms promoting it across connected devices are in near-permanent "beta" stages of development, being and becoming at the

The loss of control you fear is already in the past. - Clay Shirky same time, both As-Is and To-Be. In all instances, success hinges on a plausible promise, effective Web 2.0 applications, and an acceptable bargain with users. ${ }^{4}$ Meaning is the new message.

The world may not yet be flat but technology is most assuredly leveling organizations and the silos in them: users have been given the tools to do things together in networks and no longer rely exclusively on the traditional structures, viz., functional, geographical, product, customer/market, or matrix organizations, that up to this time had enabled them to collaborate and contribute to serve common aims in (the lower echelons of) the hierarchy of needs. ${ }^{5}$ They are newly empowered and emboldened. Specifically, with positive (and, to the

As far as the customer is concerned, the interface is the product.

一Jef Raskin unprepared, negative) ramifications, information is far more transparent than in the past; users can access up-to-date information instantly on any topic; there are few barriers to involvement; and online communities therefore coalesce all of a sudden.

\section{Creating Value in Communities}

Social communities now exist in almost every conceivable domain. However, four broad types of online communities have morphed into Web. 2.0 entities in a new, horizontal architecture of participation and connection that prizes credibility. ${ }^{6}$ They are relationship-, interest-, transaction-, and fantasy-oriented. Communities of the first type organize around (usually) intense life experiences that lead to personal bonding between members. In the second type, interactions center on topics of common interest. The third type of community revolves around facilitated buying and selling of products and services and the delivery of information that supports transactions. ${ }^{7}$ The fourth type plays roles in simulated environments.

These four types of online communities hold significant value-creation potential for users, public sector agencies, nongovernment organizations, and the private sector. Opportunities to add value through new channels lie pell-mell in content addition; subscription revenues; closer understanding of explicit or latent needs; product or service ideation or creation; and better targeting of market segments. Naturally, the scope for value creation hinges on the particulars of a community and who organizes its space. Nonetheless, well-designed and wellimplemented social media brings with it the power of every user on the planet: its influence can only grow because, unlike in the past, control is shared with the crowd and very real feedback is fast. Users generate content and voice their feelings far and wide. From "wisdom of the crowd"8 reactions, organizations can collect detailed information on users, build valuable relationships through conversations about people's experiences, deploy higher levels of engagement, and refine offerings and related messages to better match needs. The uses of social media are boundless: Web 2.0, aka the Social or Relationship Web, amounts to nothing less than a massive social experiment.

Social media is an umbrella term. At its simplest, it is the integration of technology with social interaction to create value. It rests on internet tools that enable shared community experiences through multidirectional conversations that create, organize, edit, combine, and share content.

4 See Clay Shirky. 2008. Here Comes Everybody: The Power of Organizing Without Organizations. The Penguin Press.

5 The phenomenon of Web 2.0 jives with other societal trends. They include demographic changes, the consumerization of information and communication technology, the empowerment of consumers, the gradual move from hierarchical to network-based forms of organizations, the rise of the knowledge worker, the accent on creativity and innovation, and the growing importance of informal learning.

6 For bloggers, for example, endorsement value is a function of their authority on a given topic, their network's interest in and authority on the topic, and the trust level among the network on the topic.

The chief attraction here is that social media eliminates inefficient middlemen and lowers the cost of products and services.

8 Borrowing a leaf from James Surowiecki, judicious use of Web 2.0 applications can promote the diversity of opinion, independence, decentralization, and aggregation needed to form a wise crowd. See James Surowiecki. 2004. The Wisdom of Crowds: Why the Many Are Smarter Than the Few and How Collective Wisdom Shapes Business, Economies, Societies, and Nations. Doubleday. 
Growing Web 2.0 Organizations ...

Many individuals already use Web 2.0 applications every day and consider life without these unimaginable. As time flies, a greater percentage of the population will feel the same. Already, younger personnel expect to work in organizations where Web 2.0 is the norm and are dismayed to discover that many of the applications they use in their personal lives are not available professionally. What is more, today's teenagers will soon enter the workforce.

\section{Box: Examples of Social Media Sites ${ }^{9}$}

Craigslist—classified ads. Available: www.craigslist.org/about/sites

Delicious—-social bookmarking. Available: delicious

Digg—-social news. Available: www.digg.com

Engadget—gadget news and reviews. Available: www.engadget.com/

Facebook—social networking. Available: www.facebook.com

Flickr - photo sharing. Available: www.flickr.com

Flixster-movie reviews and ratings. Available: www.flixster.com/

LinkedIn — professional networking. Available: www.linkedin.com

MyBlogLog_blog networking. Available: www.mybloglog.com

MySpace Music - music sharing. Available: www.myspace.com/

Netvibes - information aggregator. Available: www.netvibes.com/\#general

Ning — social network space. Available: www.ning.com/

NutshellMail—social network aggregation. Available: nutshellmail.com/

Second Life — virtual worlds. Available: secondlife.com

Slideshare - presentation sharing. Available: www.slideshare.net/

Twitter-microblogging. Available: twitter.com/

Wikipedia—web-based encyclopedia. Available: wikipedia.org

WordPress - open source blog publishing application. Available: wordpress.org/

Yahoo! Answers - community answers. Available: answers.yahoo.com

YouTube — video sharing. Available: www.youtube.com

Source: Author.

9 All industries and technologies experience consolidation, and social media is no exception. Many Web 2.0 applications are absorbed by others. Facebook, for instance, grew after its acquisition of FriendFeed in 2009. New entrants will continue to challenge incumbents because the Social Web allows for rapid prototyping, failure, and adaptation. 


\begin{tabular}{|c|c|}
\hline Form & Description \\
\hline Blog & $\begin{array}{l}\text { Short for web log, an editor-less, chronologically ordered journal of commentary and descriptions of events, written } \\
\text { in a conversational tone, sometimes accompanied by other material such as graphics or video, that is frequently } \\
\text { updated with permanent links to other sources and contains entries inviting comments. }\end{array}$ \\
\hline Chat & Interaction on a website with users adding text items in sequence into the same space at almost the same time. \\
\hline Crowdsourcing & $\begin{array}{l}\text { A compound of crowd and outsourcing, the broadcast by an initiating agent of problems in need of solutions to a } \\
\text { group of solvers, with convergent interests and behaviors, in the form of an open call. }\end{array}$ \\
\hline Folksonomy & $\begin{array}{l}\text { A system of classification, sometimes visualized as word clouds, derived from the method and practice of } \\
\text { collaboratively creating and managing user-defined labels or tags to annotate and categorize content. }\end{array}$ \\
\hline $\begin{array}{l}\text { Image and Video } \\
\text { Sharing Site }\end{array}$ & A user-generated website that allows users to upload pictures or videos and view and comment on those of others. \\
\hline Internet Forum & Also called a message board, a discussion area on a website where users can discuss issues with asynchronous posts. \\
\hline Mashup & $\begin{array}{l}\text { An application combining data from two or more external sources into a single integrated tool that performs a new } \\
\text { service. }\end{array}$ \\
\hline Metadata & $\begin{array}{l}\text { Structured information that describes — and allows users to find, manage, control, and understand —other } \\
\text { information. }\end{array}$ \\
\hline Microblogging & $\begin{array}{l}\text { A web service that allows users to write tweets and publish them to be viewed and commented upon by their } \\
\text { network. }\end{array}$ \\
\hline $\begin{array}{l}\text { Mobile Text } \\
\text { Messaging }\end{array}$ & Short messages of text exchanged between mobile devices. \\
\hline Mobile Web & A mobile device incorporating a web browser to access the internet. \\
\hline Podcast & $\begin{array}{l}\text { Audio or video "show" made available on the internet, usually through a subscription, for downloading to personal } \\
\text { computers or mobile devices. }\end{array}$ \\
\hline $\begin{array}{l}\text { Really Simple } \\
\text { Syndication Feed }\end{array}$ & $\begin{array}{l}\text { A file that contains regularly updated information such as news headlines or blog posts and can be subscribed to } \\
\text { using aggregators or newsreaders. }\end{array}$ \\
\hline $\begin{array}{l}\text { Social } \\
\text { Bookmarking }\end{array}$ & A method enabling users to store, organize, search, and manage bookmarks of websites. \\
\hline Social Media & $\begin{array}{l}\text { Online technologies and practices that users leverage to share concepts, experiences, insights, opinions, and } \\
\text { perspectives in social interface. }\end{array}$ \\
\hline Social Networking & $\begin{array}{l}\text { The process of engaging in online communities, typically through "groups" and "friends lists", that allows users to } \\
\text { connect and interact with like-minded parties. }\end{array}$ \\
\hline Tweet & $\begin{array}{l}\text { A single message or status update of up to } 140 \text { characters that can be read by users following individuals on Twitter, } \\
\text { a microblogging service, or the act of posting it. }\end{array}$ \\
\hline Virtual World & $\begin{array}{l}\text { A computer-based simulated game environment in which users interact with one another via avatars, viz., virtual } \\
\text { representations of themselves, typically in the form of two- or three-dimensional cartoonish representations of } \\
\text { humanoids. }\end{array}$ \\
\hline Widget & $\begin{array}{l}\text { Also called a gadget, badge, or applet, a piece of self-contained, transportable code, often displayed in a small box, } \\
\text { that can be embedded into a website or program to perform a specific function, such as providing weather forecasts } \\
\text { or news. }\end{array}$ \\
\hline Wiki & $\begin{array}{l}\text { Collaborative publishing technology, often taken to mean a collection of webpages that allows users to work on and } \\
\text { modify content online with appropriate version control. }\end{array}$ \\
\hline
\end{tabular}

Source: Author.

10 Social media builds on existing platforms for communication and collaboration. They include face-to-face meetings, telephone calls, paper mail, fax, and so on. Those where information and communication technologies come to the fore include electronic mail, instant messaging, desktop sharing, person availability, video conferencing, Voice over Internet Protocol, and web conferencing. 
If your target audience isn't listening, it's not their fault, it's yours.

-Seth Godin
This groundswell invites public sector agencies, nongovernment organizations, and the private sector to engage, innovate, and create relevance according to the types of relationships they want. Organizations and Web 2.0 are not the easiest fit: sometimes, a cultural shift must happen for technology to make a difference. But all must learn how to stay nimble and flexible in an everchanging digital environment.

Elements of the private sector have begun to thrive on opportunities to forge, build, and deepen relationships with people, both internally and externally. From the early adoption of Web 2.0 applications such as blogs and wikis, they are expanding the mix of tools and shifting from using them experimentally to embedding them in business processes. ${ }^{11}$ Some are transforming organizational structures and opening corporate ecosystems in consequence, for example, by encouraging clients, audiences, and partners to join them in developing products. They can now reach mass audiences, target niche markets, craft messages, and create great client experiences, cost-effectively, in ways they only dreamed about before. To build Web 2.0-friendly cultures that are transparent, agile, creative, user-centric, and empowering these high-performance organizations at once asked themselves:

- How can we use Web 2.0 applications to be more successful?

- How can we leverage them to fuse the knowledge, skills, and resources of clients, audiences, and partners?

- How will they change the way we operate?

- How can they help us protect and nurture our brand and reputation?

- How can we use them to identify, recruit, develop, deploy, and retain talent?

- How can we ensure that the information we do not want to share stays in-house?

... in the Public Sector ...

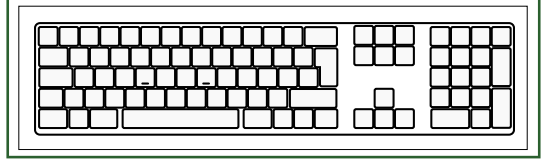

Driven by internally focused objectives rather than a service-delivery mentality, bureaucratic in decision making, traditionally slow to change, saddled with top-down hierarchical structures in which positional authority no longer compels, the public sector is a relative newcomer to social media. On the social technographics ladder, most public sector organizations are inactives ${ }^{12}$ that continue to rely on yesterday's technology to address tomorrow's problems..$^{13}$ They must change their world or the world will change them. Accepting that the internet is increasing the economic and social value of the information they hold and harvest, they must stretch mindsets to understand emerging mental models and equip themselves with the right policies, strategies, resources, delivery mechanisms, and management skills to take part in collaborative relationships in the digital economy. Why should they do so? First, the public sector bears social responsibility for embracing change-else, it faces reputational risk. Second, the social media will soon play a major role in defining how public sector organizations are considered: their accomplishments are measured not just by what they do but also, more and more, by perceptions of that. ${ }^{14}$ Third, and most important, Web 2.0 applications offer unprecedented opportunities to achieve more simple,

11 Internally, in declining order of incidence, the primary purposes of Web 2.0 applications are to manage knowledge, foster collaboration across the organization, enhance corporate culture, conduct training, and develop products and services. When interfacing with clients, audiences, and partners, again in declining order of incidence, the main objectives are to improve customer service, acquire new customers in existing markets, invite customer contributions to product development, and enable customers to interact. See McKinsey \& Co. 2008. Building the Web 2.0 Enterprise. McKinsey Quarterly. July.

12 See Charlene Li and Josh Bernoff. 2008. Groundswell: Winning in a World Transformed by Social Technologies. Harvard Business School Publishing. At the top of the ladder are creators (who publish and upload). They are followed in turn by critics (who post ratings and reviews, comment, and contribute to internet forums and wikis); collectors (who organize content using RSS feeds, tags, and voting sites); joiners (who connect in social networks such as Facebook and MySpace); spectators (who read blogs, watch videos, listen to podcasts, and read online forums and ratings and reviews); and inactives (who neither create nor consume social content of any kind).

13 In some of them, to break the fetters of command-and-control, communities and networks of practice spontaneously come together using team collaboration and content-sharing software such as Lotus Quickr.

14 Every organization has a brand and that is constantly under threat. Clients, audiences, and partners have always had an idea about what brands signify, and their ideas may vary from the images organizations are trying to project. Web 2.0 applications elicit opinions in real time. 
user-oriented, transparent, accountable, participative, inclusive, responsive, joined-up, networked, and efficient government. ${ }^{15}$ To reap these, public sector organizations must meet people where they are. Increasingly, that is online. All the time more, they will need to be aided by third parties acting as intermediaries in providing more granular,

Decision by democratic majority vote is a fine form of government, but it's a stinking way to create.

_Lillian Hellman or component-based, content and services, with implications for the design of these.

For Web 2.0 applications, the most favorable context is high trust, collaborative, and knowledge intensive. Three aspects, all having to do with management (including that of human resources), favor success on the Social Web: a lack of internal barriers to Web $2.0,{ }^{16}$ a culture that favors cooperation, and early adoption of Web 2.0 applications for communication, interaction, and service. (Web 2.0, as much else, is about people, not technology.) For this, public sector organizations must develop social media strategies across multiple networks, both internally and externally focused: from how their personnel should conduct themselves as employees ${ }^{17}$ to what is considered competition. The transition they must accomplish requires strong leadership for engagement by senior managers (whom most surveys discover cannot easily grasp the potential returns from Web 2.0); competency in forging, building, and deepening relationships on the internet; policies to both protect organizational assets and ensure appropriate personnel behavior; ${ }^{18}$ and, finally, training so that everyone understands Web. 2.0 applications, how to use them in the context of the organization, and their respective roles.

\section{... in Quick Steps}

In the 21 st century, three broad challenges are plain to see: emerging global issues, rising citizen expectations, and aging populations. In the age of the internet, Web 2.0 applications dictate how responsive the public sector must be. ${ }^{19}$ A shared vision for the journey necessarily encompasses stakeholders (who to engage with), reason (rationale for acting), activity (what to do), and tools (how to do it). In quick steps, public sector organizations can start with the following: ${ }^{20}$

- Edify the organization by helping personnel at all levels realize what Web 2.0 applications are and how they can help it recognize and manage fast-evolving explicit or latent needs.

- Craft social media policies that capitalize on the benefits of adopting Web 2.0 applications in the organization, including policies for individual departments.

15 Social media can (i) amplify access to clients, audiences, and partners and improve the accessibility of the public sector's communications; (ii) enable the public sector to be more active in its relationships; (iii) offer greater scope to adjust or refocus communications quickly, where necessary; (iv) improve the long-term cost effectiveness of communications; (v) benefit from the credibility of nongovernment channels; (vi) speed feedback and input; (vii) reach market segments on specific issues; and (vii) reduce the public sector's dependence on traditional media channels and counter inaccurate press coverage.

16 Potential barriers stem from demographics, reliance on outdated hardware or software that cannot access or use Web 2.0 applications, and institutional blockers from various units. In the public sector, blockers typically include offices of information systems and technology, external relations, and the general counsel as well as line managers. Tools of control cannot be condoned but legitimate concerns over legal, privacy, and information technology issues; media and communications; and security should be addressed through policy, process, education, and training

17 See, for instance, IBM. 2010. IBM Social Computing Guidelines. Available: www.ibm.com/blogs/zz/en/guidelines.html. The guidelines give advice for appropriate behavior by personnel when they interface on blogs, wikis, social networks, and virtual worlds. Personnel are expected to act professionally, respectfully, and responsibly. The guidelines are measured and balance the need to protect the company while encouraging collaboration, creativity, and innovation. They recognize that personnel need to make their own decisions about the extent of their contributions.

18 The key is risk management, not risk avoidance. The spectrum of activities of a public servant on the Social Web, for example, ranges from the individual to the professional to the official. As an individual, he or she might express private views and take part in social networks in both private and professional capacities. As a professional, he or she might explore alternatives or present authoritative views. As an official, he or she might discuss the organization's policies or represent them.

19 Usefully, the Organisation for Economic Co-operation and Development has articulated 13 principles to provide a general framework for the wider and more effective use of public sector information and content and the generation of new uses from it. They relate to openness, access and transparent conditions for reuse, asset lists, quality, integrity, new technologies and long-term preservation, copyright, pricing, competition, redress mechanisms, public-private partnerships, international access and use, and best practices. Some would argue that timeliness and metadata should have been given more prominence in the list. See OECD. 2008. OECD Recommendation of the Council for Enhanced Access and More Effective Use of Public Sector Information. Available: www.oecd.org/dataoecd/0/27/40826024.pdf

20 Wider scope can be found in (i) identifying problems, opportunities, or future issues; (ii) policy consultations; (iii) service and service delivery; and (iv) promotion and communication. 
- Formulate social media strategies that delineate clear priorities and determine the opportunity or requirement for online collaboration aligned to evolving organizational mandates.

- Evaluate existing technologies to determine their compatibility with morphing Web 2.0 applications.

- Launch internal and external pilots that, with an eye to authenticity as well as risk and governance frameworks, identify and act on specific opportunities to drive early success and enable departments to familiarize themselves with Web 2.0 applications, understand the management required, and refine their objectives for subsequent initiatives.

- Define broader scopes for online engagement as a new way of working through the lifecycle of listen and identify, inform, consult and involve, and collaborate and empower.

- Measure engagement by focusing on the usability of Web 2.0 applications and the extent of engagement as a result of their use.

- Gauge effectiveness by examining the degree to which Web 2.0 applications help create new relevant knowledge and solve cases.

- Inculcate a culture of collaboration by relentlessly progressing how interactions with clients, audiences, and

You can never cross the ocean unless you have the courage to lose sight of the shore. -Christopher Columbus partners take place inside and outside of the organization.

- Foster organizational learning from pilots and regular initiatives based on measurements of engagement and effectiveness and comments from clients, audiences, and partners.

\section{Further Reading}

ADB. 2009a. Writing Weblogs. Manila. Available: www.adb.org/documents/information/knowledge-solutions/ writing-weblogs.pdf

- 2009b. Collaborating with Wikis. Manila. Available: www.adb.org/documents/information/knowledgesolutions/collaborating-with-wikis.pdf

Don Tapscott and Anthony Williams. 2006. Wikinomics: How Mass Collaboration Changes Everything. Atlantic Books.

Government 2.0 Taskforce. 2009. Engage: Getting on with Government 2.0: Report of the Government 2.0 Taskforce. Available: www.finance.gov.au/publications/gov20taskforcereport/doc/government20taskforcereport.pdf

\section{For further information}

Contact Olivier Serrat, Head of the Knowledge Management Center, Regional and Sustainable Development Department, Asian Development Bank (oserrat@adb.org). 


\section{Knowledge
Solutions}

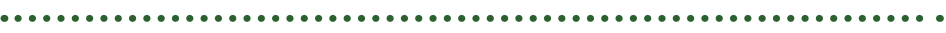

Asian Development Bank

ADB's vision is an Asia and Pacific region free of poverty. Its mission is to help its developing member countries reduce poverty and improve the quality of life of their people. Despite the region's many successes, it remains home to two thirds of the world's poor: 1.8 billion people who live on less than $\$ 2$ a day, with 903 million struggling on less than $\$ 1.25$ a day. $A D B$ is committed to reducing poverty through inclusive economic growth, environmentally sustainable growth, and regional integration.

Based in Manila, ADB is owned by 67 members, including 48 from the region. Its main instruments for helping its developing member countries are policy dialogue, loans, equity investments, guarantees, grants, and technical assistance.

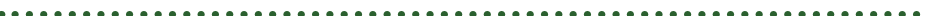

Knowledge Solutions are handy, quick reference guides to tools,

methods, and approaches that propel development forward and enhance its effects. They are offered as resources to ADB staff. They may also appeal to the development community and people having interest in knowledge and learning.

The views expressed in this publication are those of the author(s) and do not necessarily reflect the views and policies of the Asian Development Bank $(A D B)$ or its Board of Governors or the governments they represent. $A D B$ encourages printing or copying information exclusively for personal and noncommercial use with proper acknowledgment of ADB. Users are restricted from reselling, redistributing, or creating derivative works for commercial purposes without the express, written consent of ADB.

Asian Development Bank

6 ADB Avenue, Mandaluyong City

1550 Metro Manila, Philippines

Tel +6326324444

Fax +6326362444

knowledge@adb.org

www.adb.org/knowledgesolutions 